\title{
Epigenetic Regulation in Prostate Cancer Progression
}

\author{
Katia Ruggero $^{1}$ • Sonia Farran-Matas ${ }^{1} \cdot$ Adrian Martinez-Tebar $^{1}$ • Alvaro Aytes ${ }^{1,2}$ \\ Published online: 18 April 2018 \\ (C) The Author(s) 2018, corrected publication May/2018
}

\begin{abstract}
Purpose of Review An important number of newly identified molecular alterations in prostate cancer affect gene encoding master regulators of chromatin biology epigenetic regulation. This review will provide an updated view of the key epigenetic mechanisms underlying prostate cancer progression, therapy resistance, and potential actionable mechanisms and biomarkers.

Recent Findings Key players in chromatin biology and epigenetic master regulators has been recently described to be crucially altered in metastatic CRPC and tumors that progress to AR independency. As such, epigenetic dysregulation represents a driving mechanism in the reprograming of prostate cancer cells as they lose AR-imposed identity.

Summary Chromatin integrity and accessibility for transcriptional regulation are key features altered in cancer progression, and particularly relevant in nuclear hormone receptor-driven tumors like prostate cancer. Understanding how chromatin remodeling dictates prostate development and how its deregulation contributes to prostate cancer onset and progression may improve risk stratification and treatment selection for prostate cancer patients.
\end{abstract}

Keywords Prostate cancer · Epigenetics · Transcriptional regulation $\cdot$ Chromatin biology $\cdot$ Androgen receptor $\cdot$ Drug targets

\section{Introduction}

Prostate cancer has traditionally been seen as an aging-associated, low mutational load tumor with a tendency for genomic rearrangements and a particular dependency on the activity of the androgen receptor (AR). As such, treatment strategies have been focused on targeting the AR axis, either through inhibiting steroidogenic pathways and the production of testosterone, or by antagonizing the AR itself to prevent its nuclear translocation and the activation of its transcriptional network. While these strategies have doubtlessly improved survival for prostate cancer patients, they are not curative in many cases, and resistance eventually occurs in about $30 \%$ of

This article is part of the Topical Collection on Molecular Biology of Prostate Cancer

Alvaro Aytes

aaytes@idibell.cat

1 Programs of Molecular Mechanisms and Experimental Therapeutics in Oncology (ONCOBell), Catalan Institute of Oncology, Bellvitge Institute for Biomedical Research, Granvia de l'Hopitalet, 199 08908, L'Hospitalet de Llobregat, 08907 Barcelona, Spain

2 Programs of Cancer Therapeutics Resistance (ProCURE), Catalan Institute of Oncology, Bellvitge Institute for Biomedical Research, L'Hospitalet de Llobregat, 08907 Barcelona, Spain patients, who develop castration-resistant prostate tumors (CRPC) for which limited treatment options exist. Moreover, under the CRPC definition, a pool of diverse disease presentations with variable outcomes exists, including neuroendocrine tumors.

Massive parallel sequencing of hundreds of tumor specimens from prostate cancer patients at different stages of cancer progression has provided an accurate picture of the landscape of genetic alterations that accompany cancer evolution in the prostate. Yet, despite several molecular classification systems for prostate tumors have been proposed, clear association with risk stratification remains to be provided. On the other hand, whether these genetic classifiers predict treatment outcome and to what extent genetic alterations in prostate cancer can be exploited for personalized therapies is yet to be proven. Interestingly, together with well-known drivers of cancer progression, an important number of new alterations have been described, with an intriguing enrichment of those affecting key players in chromatin biology and epigenetic master regulators (see a summary in Table 1). This is particularly relevant in metastatic CRPC and tumors that have transitioned to ARindependent phenotypes after progressing on the newest antiandrogen drugs.

Here, we introduce key concepts to understand how epigenetic dysregulation is a plausible driving mechanism in the 
Table 1 Summary of epigenetic master regulators implicated in prostate cancer

\begin{tabular}{|c|c|c|}
\hline Gene name & Function in prostate cancer & References \\
\hline \multicolumn{3}{|l|}{ Methyltransferases } \\
\hline NSD2 & $\begin{array}{l}\text { H3K36 di-methyltransferase. Promotes prostate cancer } \\
\text { tumorigenesis and progression. It is overexpressed in } \\
\text { metastatic stage and associated with biochemical recurrence }\end{array}$ & {$[1 \bullet \bullet, 2,3]$} \\
\hline EZH2 & $\begin{array}{l}\mathrm{H} 3 \mathrm{~K} 27 \text { di- and tri-methyltransferase. Member of the polycomb } \\
\text { repressive complex 2, crucial driver of prostate oncogenesis }\end{array}$ & {$[4,5]$} \\
\hline SUV39H1 (KMT1A) & H3K9 tri methyltransferase. Enhance prostate cancer cell & {$[6,7]$} \\
\hline \multicolumn{3}{|l|}{ SETDB1 (KMT1E) } \\
\hline SUV39H2 (KMT1B) & $\begin{array}{l}\text { H3K9 tri methyltransferase increases androgen-dependent tran- } \\
\text { scriptional activity by interacting with the AR }\end{array}$ & {$[8]$} \\
\hline SMYD3 & $\begin{array}{l}\mathrm{H} 3 \mathrm{~K} 4 \text { di- and methyltransferase, promotes cell proliferation and } \\
\text { migration }\end{array}$ & {$[9,10]$. } \\
\hline PRMT5 & $\begin{array}{l}\text { Drives prostate cancer cell growth through epigenetic } \\
\text { inactivation of several tumor suppressors through histone } \\
\text { arginine methylation at H4R3. Enhances AR-targeted gene } \\
\text { expression }\end{array}$ & $\begin{array}{l}{[11,12 \bullet} \\
13]\end{array}$ \\
\hline \multicolumn{3}{|l|}{ Demethylases } \\
\hline LSD1 & $\begin{array}{l}\mathrm{H} 3 \mathrm{~K} 9 \text { and } \mathrm{H} 3 \mathrm{~K} 4 \text { demethylase involved in prostate cancer } \\
\text { recurrence, } \mathrm{CRPC} \text {, and poor survival. Regulates } \mathrm{AR} \\
\text { transcriptional activity in a context-dependent manner }\end{array}$ & $\begin{array}{c}{[14 \bullet \bullet, 15,} \\
16 \bullet]\end{array}$ \\
\hline JARID1B (KDM5B) & $\begin{array}{l}\text { H3K4 mono, di-, and tri-demethylase. AR coactivator regulating } \\
\text { its transcriptional activity. Upregulated in prostate cancer } \\
\text { tissues }\end{array}$ & {$[17,18]$} \\
\hline JARID1C (KDM5C) & $\begin{array}{l}\mathrm{H} 3 \mathrm{~K} 4 \mathrm{di} \text { - and tri-demethylase overexpressed in prostate cancer. } \\
\text { Proposed as a predictive marker for therapy failure in patients } \\
\text { after prostatectomy }\end{array}$ & [19]. \\
\hline JARID1D (KMD5D) & $\begin{array}{l}\text { H3K4 di- and tri-demethylase. Suppress invasion and progres- } \\
\text { sion of prostate cancer. Low levels were associated with poor } \\
\text { prognosis and resistance to docetaxel }\end{array}$ & {$[20,21]$} \\
\hline PHF8 & $\begin{array}{l}\mathrm{H} 3 \mathrm{~K} 9, \mathrm{H} 3 \mathrm{~K} 27 \text {, and } \mathrm{H} 4 \mathrm{~K} 20 \text { demethylase. Transcriptional } \\
\text { coactivator of AR. Promotes prostate cancer cell proliferation, } \\
\text { migration, invasion, and neuroendocrine differentiation. Its } \\
\text { expression highly correlated with poor prognosis and is } \\
\text { induced by hypoxia }\end{array}$ & {$[22-29]$} \\
\hline JMJD2A (KDM4A) & H3K9 and H3K36 tri demethylases. Modulates AR & {$[30,31]$} \\
\hline JMJD2C (KDM4C) & $\begin{array}{l}\text { transcriptional activity stimulating ligand-independent gene } \\
\text { transcription via H3K9 demethylation }\end{array}$ & \\
\hline JMJD1A (KDM3A) & $\begin{array}{l}\mathrm{H} 3 \mathrm{~K} 9 \text { mono- and di-demethylase. Regulates AR activity by re- } \\
\text { cruitment to target genes only in the presence of androgens }\end{array}$ & {$[32,33]$} \\
\hline JMJD2B (KDM4B), & $\begin{array}{l}\text { H3K9 tri-demethylase, AR coactivator. Regulates AR } \\
\text { transcriptional activity via demethylation activity and via } \\
\text { inhibition of ubiquitination and increased AR stability }\end{array}$ & {$[34]$} \\
\hline JMJD3 (KDM6B) & $\begin{array}{l}\mathrm{H} 3 \mathrm{~K} 27 \text { di- and tri-demethylase overexpressed in metastatic } \\
\text { prostate cancer }\end{array}$ & [35]. \\
\hline \multicolumn{3}{|l|}{ DNA methylation } \\
\hline DNMTs & $\begin{array}{l}\text { Control of transcriptional program during prostate cancer and } \\
\text { CRPC progression }\end{array}$ & {$[36]$} \\
\hline GSTP1 & $\begin{array}{l}\text { Silencing of GSP1 upon promoter hypermethylation is a } \\
\text { potential prognostic biomarker and occurs early during } \\
\text { prostate carcinogenesis }\end{array}$ & [37-39] \\
\hline \multicolumn{3}{|l|}{ Histone acetylation } \\
\hline P300 & $\begin{array}{l}\text { Histone acetyltransferase. Besides canonical histone acetylation } \\
\text { activity, it acetylates the AR and enhances its transcriptional } \\
\text { activity (coactivator) and drives prostate cancer growth }\end{array}$ & {$[40,41]$} \\
\hline SIRT1 & $\begin{array}{l}\text { Histone deacetylase; regulates cellular growth through AR } \\
\text { deacetylation }\end{array}$ & {$[42,43]$. } \\
\hline SIRT2 & $\begin{array}{l}\text { Histone deacetylase; its downregulation has been associated with } \\
\text { increased acetylated H3K18 and poorer outcome and } \\
\text { decreased sensitivity to androgen deprivation therapy }\end{array}$ & [44] \\
\hline \multicolumn{3}{|c|}{ BET bromodomain epigenetic readers } \\
\hline BRD4 & & \\
\hline
\end{tabular}


Table 1 (continued)

\begin{tabular}{|c|c|c|}
\hline Gene name & Function in prostate cancer & References \\
\hline & $\begin{array}{l}\text { Bromodomain and extra-terminal protein, interacts with } \mathrm{AR} \text { and } \\
\text { promote its activity and antiandrogen resistance }\end{array}$ & $\begin{array}{l}{[45 \cdot} \\
46-48]\end{array}$ \\
\hline TRIM24 & $\begin{array}{l}\text { Epigenetic reader and transcription co-regulator, overexpressed } \\
\text { in CRPC and associated to disease recurrence. Required for } \\
\text { prostate cancer cell proliferation in CRPC }\end{array}$ & [49]. \\
\hline CHD1 & $\begin{array}{l}\text { H3K4me2-3 epigenetic reader whose loss is related with prostate } \\
\text { cancer aggressiveness and DNA repair defects, thus } \\
\text { sensitizing tumor cells to PARP inhibitors }\end{array}$ & {$[50,51]$} \\
\hline \multicolumn{3}{|c|}{ Pioneer transcription factors } \\
\hline FOXA1 & $\begin{array}{l}\text { FOXA1 activity on chromatin results in increased accessibility } \\
\text { and increased chromatin-bound AR. High FOXA1 expression } \\
\text { leads to a restricted AR cistrome regulation. FOXA1 also has } \\
\text { the potential to reprogram GATA2 }\end{array}$ & {$[52,53]$} \\
\hline GATA2 & $\begin{array}{l}\text { GATA2 activity in human prostate cancer is strongly associated } \\
\text { to AR levels and is hence considered a prostate cancer } \\
\text { oncogene }\end{array}$ & {$[53-55]$} \\
\hline \multicolumn{3}{|c|}{ Epigenetic regulators of lineage plasticity } \\
\hline SOX2 & $\begin{array}{l}\text { Overexpressed TF in prostate cancer, regulating CRPC } \\
\text { proliferation, and evasion of apoptosis. Promotes tumor } \\
\text { metastasis by inducing EMT. Associated to NEPC emergence }\end{array}$ & $\begin{array}{r}{[56-61} \\
62 \bullet \bullet \\
63 \bullet \bullet]\end{array}$ \\
\hline MYC & $\begin{array}{l}\text { Master regulator of prostate cancer transcriptional program. } \\
\text { Associated with prostate cancer recurrence and poor prognosis }\end{array}$ & {$[64,65]$} \\
\hline MYCN & $\begin{array}{l}\text { Driver of NEPC by inducing an EZH2-mediated transcriptional } \\
\text { program }\end{array}$ & {$[64,66]$} \\
\hline \multicolumn{3}{|c|}{ Oncogenic pathways } \\
\hline Hsp90 & $\begin{array}{l}\text { Initiates ERK signaling and leads to the recruitment of EZH2 to } \\
\text { the E-cadherin promoter and repression of E-cadherin } \\
\text { expression, driving EMT and invasion in prostate cancer cells }\end{array}$ & [67]. \\
\hline DAB2IP & $\begin{array}{l}\text { Tumor suppressor Ras-GAP. Negatively controls Ras-dependent } \\
\text { mitogenic signals and modulates } \mathrm{TNF} \alpha / \mathrm{NF}-\mathrm{kB} \\
\mathrm{WNT} / \beta \text {-catenin, PI3K/AKT, and androgen receptors path- } \\
\text { ways }\end{array}$ & [68-70]. \\
\hline RB1 & $\begin{array}{l}\text { This tumor suppressor gene is commonly loss in metastatic and } \\
\text { antiandrogen resistant prostate cancer and NEPC. Directly } \\
\text { repress the expression of Sox } 2 \text { and Ezh2 }\end{array}$ & $\begin{array}{r}{[71,72} \\
63 \bullet \bullet]\end{array}$ \\
\hline ACK1 & $\begin{array}{l}\text { Tyrosine kinase correlated with poor prognosis and interacts with } \\
\text { AR to drive ADT resistance and CRPC growth. Regulates } \\
\text { transcription of AR and AR-v7 via epigenetic regulation }\end{array}$ & [72-74] \\
\hline
\end{tabular}

reprograming of prostate cancer cells as they lose ARimposed identity. Beyond reviewing the current status of epigenetic biomarkers and classifiers and their clinical impact, we will discuss the scientific basis for therapeutic targeting master regulators of chromatin remodeling and integrity and the current state of epigenetic drugs for prostate cancer.

\section{DNA Methylation and Histone Modifications in Prostate Carcinogenesis}

Perturbed DNA methylation patterns have long been reported during prostate cancer progression [75]. Among the most well-described alterations is the GSTP1 promoter hypermethylation and subsequent silencing [37], which is thought to occur early during prostate carcinogenesis [38] and has thus been proposed as a potential prognostic biomarker [39]. Yet, numerous other key genes have been implicated in DNA methylation changes. In fact, the promoter of the Androgen Receptor (AR) itself appears to be hypermethylated in up to $30 \%$ of CRPCs, resulting in the loss of AR expression [76]. Moreover, PTEN silencing is often a consequence of promoter CpG islands hypermethylation [77], while hypermethylation of the p16 tumor suppressor gene is associated with a proliferative advantage, thus contributing to carcinogenesis and disease progression [78]. Similarly, the hypomethylation and consequent upregulation of genes like heparanase and urokinase plasminogen activator ( $\mathrm{UPA}$ ) was reported to contribute to tumor cell invasion and metastasis [79]. More globally, DNA methylation signatures have been identified and proposed as molecular biomarkers of prostate cancer progression and treatment response [80].

Histone modifications also play an important role in the progression of many tumor types including prostate cancer. 
Lysine methyltransferases (KMT) and demethylases (KDM) are important epigenetic histone modifiers implicated in the control of gene transcriptional regulation as well as in nonhistone protein posttranslational modifications and activity modulation [81]. More specifically, SUV39H1 (KMT1A) and SETDB1 (KMT1E) have been shown to enhance prostate cancer cell migration and invasion and to be upregulated in human prostate cancer specimens, and hence suggested as potential therapeutic targets [6], while SUV39H2 (KMT1B) interacts with the AR to increase androgen-dependent transcriptional activity [8]. Furthermore, levels of SETDB1 have been recently associated with prognosis and the development of bone metastases from prostate cancer [7]. Similarly, SET and MYND domain-containing protein 3 (SMYD3) has also been identified as an upregulated $\mathrm{H} 3$ and $\mathrm{H} 4$ lysine methyltransferase promoting cell proliferation and migration, thus emerging as a predictive marker of prostate cancer [10]. Alternatively, protein arginine methyltransferase 5 (PRMT5) was described as a prostate cancer oncogene driving cancer cell growth through epigenetic inactivation of several tumor suppressors [11] through histone arginine methylation at H4R3. PRMT5 has also recently been shown to enhance AR-targeted gene expression by arginine methylation and interaction with the transcription factor Sp1 [13].

Demethylases also play an important role in prostate cancer development. Lysine-specific demethylase 1 (LSD1/KDM1A) has been proposed as an oncogene whose overexpression has been positively correlated with the malignancy of many cancer types, including prostate [14••, 82], promoting carcinogenesis by multiple mechanisms. Increased LSD1 expression is associated with prostate cancer recurrence and poor survival and appears to have distinct functions in androgen-dependent $[14 \bullet \bullet, 83]$ and refractory prostate cancer [15]. Recently, it was discovered that LSD1 is a co-regulator of vitamin $\mathrm{D}$ receptor activity in prostate cancer and its expression is correlated with shorter progression-free survival in primary and metastatic patients [84]. In a recent study, it was found that LSD1-mediated epigenetic reprogramming drives $\mathrm{CRPC}$ and was associated with the activation of CENPE, which was regulated by the cobinding of LSD1 and AR to its promoter region, which was associated with loss of RB1 [16 ${ }^{\bullet}$.

The overexpression of other histone demethylases (HDMs) has also been observed in prostate cancer. An exhaustive functional screen [27] identified 32 enzymes belonging to the family of JmjC domain-containing histone demethylases as critical for prostate cancer proliferation and survival. KDM5 family members are H3K4 demethylases; JARID1B (KDM5B) is upregulated in prostate cancer tissues and acts as an AR coactivator [17], while JARID1C (KDM5C), overexpressed in prostate cancer, emerged as a predictive marker for therapy failure in patients after prostatectomy [19]. JARID1D (KMD5D) was found to suppress the invasion and progression of prostate cancer cells; thus, it is highly downregulated in metastatic prostate tumors and those low levels were associated with poor prognosis [20]. In addition, KDM5 loss has been associated with resistance to docetaxel in prostate cancer [21]. The PHD-finger protein 8 (PHF8) is a histone demethylase and a transcriptional coactivator of AR via H4K20 demethylation [28]. Its expression, highly correlated with poor prognosis, is induced by hypoxia and promotes prostate cancer cell proliferation, migration and invasion [28], and neuroendocrine differentiation [29].

\section{The Histone Methyltransferase NSD2}

NSD2 (nuclear receptor binding SET domain protein 2), also known as WHSC1 (Wolf-Hirschhorn syndrome candidate 1) and MMSET (multiple myeloma SET domain), is a member of the histone methyltransferase NSD family of proteins also including NSD1 and NSD3. NSD2 catalyzes the dimethylation of histone $\mathrm{H} 3$ at lysine 36 (H3K36me2), a permissive mark associated with open chromation conformation and active gene transcription [85]. NSD2 was first linked to oncogenesis by the involvement in the $t(4 ; 14)$ translocation identified in up to $20 \%$ of multiple myeloma patients [86]. In the past years, NSD2 has been shown to be overexpressed in a variety of solid tumors including prostate cancer, where it has been found overexpressed in metastatic PCa compared to primary tumors and is associated with biochemical recurrence $[1 \bullet \cdot]$. Further In vitro studies strengthened the role of NSD2 in prostate cancer tumorigenesis; it has been shown that NSD2 modulates Twist family bHLH transcription factor 1 (TWIST1) to promote epithelial to mesenchymal transition and invasiveness in prostate cancer cell lines [2]. Moreover, Asangani and colleagues had reported that EZH2 mediates the overexpression of NSD2 and that the oncogenic properties of EZH2 are NSD2 dependent [3]. Interestingly, transcriptional targets of NSD2 in prostate cancer cells are highly enriched for components of the NF-kB-network, including IL-6, IL-8, survivin/Birc5, and VEGFA. In fact, NSD2 has been linked to constitutive activation of NF-kB signaling in CRPC, promoting cancer cell proliferation and survival via an autocrine positive loop in which NSD2 expression is in turn stimulated by inflammatory cytokines, such as TNF $\alpha$ and IL-6, via NF-kB [87].

Very recently, work from Li and collaborators showed that NSD2 is activated in PTEN null tumors by the AKT pathway and that its expression is required for metastatic progression. Mechanistically, AKT-mediated phosphorylation of NSD2 prevents its degradation by CRL4 ${ }^{\mathrm{Cd} 2}$ E3 ligase leading to NSD2 stabilization and overexpression. By directly inducing RICTOR expression, NSD2 mediates a positive feedback loop sustaining AKT signaling [1・•].

Finally, NSD2 has been shown to physically interact with the AR DNA-binding domain and to be recruited to the 
enhancer region of the PSA gene and enhance AR transcriptional activity [88], suggesting that NSD2 might be implicated in resistant to ADT or androgen signaling inhibition. Of note is the recent identification of NSD2 as a candidate gene promoting androgen independence through an unbiased insertional mutagenesis screen [89]. In fact, unpublished data and data from our laboratory currently under peer-review for publication strongly suggest that NSD2 is an actionable mechanism in CRPC.

\section{Epigenetic Control of Androgen Receptor Activity}

Histone modifying enzymes, and LSD1 in particular, are among the best-known modulators of AR transcriptional activity. LSD1 is an important enzyme involved in AR regulation and prostate cancer that interacts with AR and can stimulate [14••] or suppress [15] the transcriptional expression depending on promoter/enhancer context. This interaction promotes ligand-dependent transcription of AR target genes, resulting in enhanced tumor cell growth. Its coactivator activity seems to be associated with $\mathrm{H} 3 \mathrm{~K} 9 \mathrm{me} 1,2$ demethylation leading to transcriptional de-repression of AR target genes [14••]. Intriguingly, LSD1 also plays a role as co-repressor, via $\mathrm{H} 3 \mathrm{~K} 4 \mathrm{me} 1,2$ demethylation [90] and the recruitment of corepressor complexes. This highlights the dual role of many chromatin remodelers and may explain why translating them to new therapeutics has so far been limited. A possible way forward may be to define the context specificities for this duality. For example, it has been shown that in high androgen levels, AR recruits LSD1 to mediate AR gene silencing [15]; however, this negative feedback loop is apparently disrupted in CRPC, where low androgen levels promote AR overexpression. Additionally, post-transcriptional modifications can regulate LSD1 activity and may become better targets; LSD1 phosphorylation [91] results in a switch of substrate from $\mathrm{H} 3 \mathrm{~K} 4 \mathrm{me} 1,2$ to $\mathrm{H} 3 \mathrm{~K} 9 \mathrm{me} 1,2$, and the promotion of its coactivator activity. Jumonji $\mathrm{C}$ domain-containing trimethyl lysine demethylases JMJD2A (KDM4A) and JMJD2C (KDM4C) also play a significant role in modulating AR transcriptional activity [30, 31], stimulating ligand-independent gene transcription via H3K9 demethylation. On the contrary, JMJD1A (KDM3A) recruitment to target genes only occurs in the presence of androgens, regulating AR activity and identifying KDM3A-dependent genes involved in androgen response, hypoxia, glycolysis, and lipid metabolism [33], again evidencing the complex balance between chromatin modifying enzymes in controlling different but interconnected cellular processes. Of note is the case of JMJD2B (KDM4B), which is an AR coactivator, emerging as a suitable therapeutic target for the treatment of prostate cancer. JMJD2B controls AR transcriptional activity via demethylation and inhibition of ubiquitination and increased AR stability [34]. Finally, JMJD3 (KDM6B) is progressively overexpressed in metastatic prostate cancer [35].

\section{Histone Acetylation and AR}

Acetylated chromatin is generally associated to active transcription and the enzymes regulating this process are histone acetyltransferases (HAT) and deacetylases (HDAC). Accordingly, acetylated histone $\mathrm{H} 3$ in the vicinity of ARbound chromatin has been shown to reduce androgen dependence in castration resistance models $[92,93]$. That is the case for canonical HAT like p300 and CREB-binding protein, which, besides canonical histone acetylation activities, have been shown to acetylate the AR and enhance its transcriptional activity [40]. Importantly, two groups have recently independently developed small molecule inhibitors targeting p300/CBP. Lasko and colleagues reported a selective catalytic p300/CBP inhibitor able to downregulate the AR transcriptional program both in castration-sensitive and castrationresistant prostate tumors and to inhibit tumor growth in CRPC xenograft models [94], while Jin and colleagues found that targeting the p300/CBP bromodomain had remarkably similar effetcs [41]. More broadly, a recent study highlights the important role of histone acetylation in prostate cancer beyond active promoters via activation of AR associated enhancers and the increase in chromatin accessibility [95•].

Conversely, a variety of HDACs are also capable of deacetylating the AR and inhibit its activity, for example via regulation of heat-shock protein 90 (Hsp90), a chaperone controlling AR nuclear localization and activation through its acetylation/deacetylation, or sirtuin 1 (SIRT1), which regulates cellular growth through AR deacetylation [42, 43]. In fact, acetylation of $\mathrm{H} 3 \mathrm{~K} 18$, putatively via downregulation of SIRT2 deacetylase, has been associated to poorer outcome and decreased sensitivity to androgen deprivation therapy (ADT). Finally, at the mechanistic level, the $\mathrm{Wu}$ lab has recently demonstrated that HDAC inhibitors can suppress HMGA-driven EMT, reduce tumor growth and metastasis and, importantly, resensitize prostate cancer cells to [96].

\section{The Role of EZH2/Polycomb Repressive Complex in Prostate Cancer}

The enhancer of zeste homolog 2 (EZH2) is a critical member of the Polycomb Repressive Complex 2 (PRC2) that regulates histone methylation mainly via lysine 27 at histone H3 (H3K27), a modification associated to transcriptional silencing [97] that is found upregulated in many tumor types. In prostate cancer, its elevated expression associates with poorer outcomes and has therefore been proposed as an oncogene [4, 98]. A major function of $\mathrm{EZH} 2$ is to repress lineage- 
specifying factors, thereby promoting stemness features [99], epithelial-mesenchymal transition (EMT), and ultimately metastatic progression [100]. A wealth of recent evidence has confirmed these previous observation in the prostate cancer field. Back-to-back recent articles in Science by the Sawyers and Goodrich groups demonstrated that lineage plasticity and neuroendocrine differentiation in androgen independence is partly driven by Ezh2 and Sox 2 in prostate cancer mouse models carrying loss of function alleles for $\mathrm{p} 53$ and $\mathrm{Rb}$ tumor suppressors $[62 \bullet \bullet, 63 \bullet \cdot$. This came to confirm two previous reports by Dardenne and colleagues [64] and by Xu and colleagues [101] showing that N-myc induces EZH2-driven neuroendocrine prostate cancer [64] and it cooperates with E2F1 in castration resistance [101].

Yet, EZH2 has also PRC2-independent roles as coactivator of transcription factors, including an AKT-dependent methylation of the AR, via PI3K/AKT phosphorylation of EZH2 at serine 21 [102], and modulation of AR recruitment to its target sites [103••]. Not surprisingly, EZH2 inhibitors are the focus of intensive development and have been widely tested in vivo [5] and in clinical trials (see Table 2 for details). Beyond a promising drug target, EZH2 and TOP2A have been proposed as prognostic as well as predictive biomarkers of treatment response against EZH2 inhibitors [104].

\section{Bromodomain-Containing Proteins in Prostate Cancer}

Bromodomain-containing proteins are chromatin readers that recognized mono-acetylated histones and trigger chromatin remodeling to initiate transcription. Mutations and deregulation of BRD-containing proteins is a common feature of a variety of cancers. More than $50 \%$ of primary and metastatic prostate tumors and more than $70 \%$ of neuroendocrine prostate cancer present genomic alterations in any of the 42 known BRD-containing proteins [105]. Further, BRD-containing proteins have a diversity of catalytic and scaffolding functions and may act as transcription factors, transcriptional co-factors recruiting other proteins in the transcriptional complex, methyltransferases, HATs, Helicases, and ATP-dependent chromatin remodelers, therefore playing a central role in gene expression regulation [106].

The subgroup of BET proteins (bromodomain and extraterminal), and in particular BRD4, have been the best characterized in prostate cancer, and several inhibitors of BET bromodomains have been developed and are currently in clinical trial (see Table 2). The conserved BET family includes BRD4, BRD2, BRD3, expressed ubiquitously, and BRDT, specifically expressed in the testis. BRD4 recognizes acetylated lysines at enhancers/superenhancer [107••, 108••] and recruits the elongation factor P-TEFb and stimulates RNA polymerase II-dependent transcription [109]. A provocative new finding by Zuber and colleagues with implications in risk assessment shows that tissue-specific SNPs in superenhancer sequence bound by BRD4 are significantly associated with increased prostate cancer risk and show better enrichment for risk loci than AR [110].

BRD4 physically interacts with high-affinity with the Nterminal domain of AR leading to AR translocation into the nucleus and AR recruitment to target loci, promoting AR activity and expression of AR target genes in CRPC [45•]. A recent study showed that the small molecule BET inhibitor ABBV-075 could disrupt the recruitment of BRD4 at enhancer of AR target genes and repress their expression, whithout affecting AR protein levels [111]. Moreover, BET proteins have a role in resistance to antiandrogens and BET inhibitors can effectively resensitize resistant tumors to enzalutamide [112]. One of these mechanisms of resistance to antiandrogens is the upregulation of the glucocorticoid receptor (GR), and the co-option of the AR regulon, thus favoring CRPC progression by overcoming AR dependency [46, 47, 113].

Beyond AR signaling, BRD4 has been shown to bind to the truncated ERG (ERG $\Delta 39)$ encoded by the TMPRSS2-ERG fusion, co-regulating the expression of ERG target genes in CRPC, thereby stimulating cell growth and invasion [114]. Additionally, SPOP, an E3 ligase substrate binding protein frequently mutated in prostate cancer, was also reported to target BET proteins for ubiquitination-mediated degradation. Interestingly, SPOP mutants fail to ubiquitinate BET proteins, leading to their stabilization and to resistance to BET inhibitors $[48,115]$. This mechanism of resistance causes activation of AKT-mTORC1 signaling and consequently resistance to BET inhibitors can be overcome by combination with AKT inhibitors [116].

It is well known that one of the major aging-associated drivers of prostate carcinogenesis is oxidative stress and its impact on DNA [117]. Interestingly, Hussong and colleagues have recently established a link between BRD4 and oxidative stress response genes in prostate cancer, such as the KEAP1/ NRF2 axis and HMOX1, and reactive oxygen species (ROS) production [118].

Other than BET, several BRD-containing proteins have been associated to prostate cancer progression and are at different validation stages for therapeutic targets in mCRPC. TRIM24, tripartite motif-containing protein 24 , is an epigenetic reader and transcription co-regulator overexpressed in CRPC and associated to disease recurrence. Recurrent SPOP mutants stabilize TRIM24 [119], enhancing AR signaling and promoting tumor growth via binding with the proteins TIP60 and BRD7 [120], which has led to the proposition of TRIM24 as an essential gene for prostate cancer cell proliferation in CRPC [49].

Finally, the role of chromodomain proteins, and in particular chromodomain helicase DNA-binding protein 1 (CHD1), has in the recent years been elucidated in the context of 
Table 2 Clinical trials for epigenetic drugs including prostate cancer patients

\begin{tabular}{|c|c|c|c|c|c|}
\hline Trial ID & Drug & Phase & Conditions & Patients & Status \\
\hline \multicolumn{6}{|c|}{ BET bromodomain inhibitors } \\
\hline NCT02259114 & OTX015/MK-8628 & I & $\begin{array}{l}\text { NUT midline carcinoma, triple negative } \\
\text { breast cancer, non-small cell lung cancer } \\
\text { (rearranged ALK or mut KRAS), CPRC, } \\
\text { pancreatic ductal adenocarcinoma }\end{array}$ & 47 & Completed \\
\hline NCT02698176 & & I & $\begin{array}{l}\text { NUT midline carcinoma, triple negative breast } \\
\text { cancer, non-small cell lung cancer, CRPC }\end{array}$ & 13 & Terminated \\
\hline NCT01987362 & & I & Solid Tumors & 120 & Active \\
\hline NCT02711956 & ZEN003694 & I & Metastatic CRPC (+enzalutamide) & 58 & Recruiting \\
\hline NCT02705469 & & I & Metastatic CRPC & 44 & Active \\
\hline NCT03266159 & GSK525762 & II & Solid tumors & 150 & Not recruiting \\
\hline NCT02419417 & BMS-986158 & $\mathrm{I} / \mathrm{II}$ & Advanced solid tumors & 150 & Recruiting \\
\hline NCT02391480 & ABBV-075 & I & $\begin{array}{l}\text { Advanced cancer, breast cancer, non-small, } \\
\text { ell lung cancer, acute myeloid leukemia, } \\
\text { multiple myeloma, prostate cancer, } \\
\text { small-cell lung cancer, non-Hodgkins lymphoma }\end{array}$ & 150 & Recruiting \\
\hline NCT02630251 & GSK2820151 & I & Advanced or recurrent solid tumors & 60 & Recruiting \\
\hline NCT02369029 & BAY 1238097 & I & Neoplasms & 8 & Terminated \\
\hline NCT02431260 & INCB054329 & $\mathrm{I} / \mathrm{II}$ & Advanced cancer & 69 & Active, not recruiting \\
\hline NCT02711137 & INCB057643 & $\mathrm{I} / \mathrm{II}$ & Advanced cancer & 230 & Recruiting \\
\hline NCT02607228 & GS-5829 & $\mathrm{I} / \mathrm{II}$ & Metastatic CRPC (+enzalutamide) & 132 & Recruiting \\
\hline NCT02711137 & INCB057643 & $\mathrm{I} / \mathrm{II}$ & $\begin{array}{l}\text { Advanced solid tumors and hematologic } \\
\text { malignancy (+abiraterone) }\end{array}$ & 420 & Recruiting \\
\hline \multicolumn{6}{|c|}{$\mathrm{EZH} 2$ and $\mathrm{PRC} 1 / 2$ inhibitors } \\
\hline NCT03213665 & Tazemetostat & II & $\begin{array}{l}\text { Advanced solid tumors, non-Hodgkin } \\
\text { lymphoma, or histiocytic (EZH2, SMARCB1, } \\
\text { or SMARCA4 mutations) }\end{array}$ & 49 & Recruiting \\
\hline NCT01897571 & & $\mathrm{I} / \mathrm{II}$ & Advanced solid tumors & 420 & Recruiting \\
\hline NCT02875548 & & II & Advanced solid tumors & 300 & Recruiting \\
\hline NCT03217253 & & I & Metastatic malignant solid neoplasm & 48 & Not recruiting \\
\hline \multicolumn{6}{|l|}{ PRMT5 inhibitor } \\
\hline NCT02900651 & MAK683 & $\mathrm{I} / \mathrm{II}$ & $\begin{array}{l}\text { Diffuse large B cell lymphoma, } \\
\text { advanced solid tumors }\end{array}$ & 113 & Recruiting \\
\hline \multicolumn{6}{|c|}{ LSD1/KDM1A inhibitors } \\
\hline NCT02712905 & INCB059872 & $\mathrm{I} / \mathrm{II}$ & Advanced cancer & 180 & Recruiting \\
\hline \multicolumn{6}{|l|}{ DNMT inhibitors } \\
\hline NCT01118741 & Disulfiram & & Prostate cancer & 19 & Completed \\
\hline NCT00503984 & Azacitidine & $\mathrm{I} / \mathrm{II}$ & Metastatic CRPC (+docetaxel, prednisone) & 22 & Terminated \\
\hline NCT00384839 & & II & CRPC & 53 & Completed \\
\hline NCT02998567 & Guadecitabine & I & $\begin{array}{l}\text { Non-small cell lung cancer, CRPC } \\
\text { (+pembrolizumab) }\end{array}$ & 35 & Not yet recruiting \\
\hline \multicolumn{6}{|l|}{ HDAC inhibitors } \\
\hline NCT01075308 & Pracinostat (SB939) & II & Metastatic CRPC & 32 & Completed \\
\hline NCT00670553 & & I & $\begin{array}{l}\text { Prostate cancer, head and neck } \\
\text { cancer, esophageal cancer }\end{array}$ & 7 & Completed \\
\hline NCT00878436 & Panobinostat (LBH589) & $\mathrm{I} / \mathrm{II}$ & CRPC (+bicalutamide) & 52 & Completed \\
\hline NCT00667862 & & II & Metastatic CRPC & 35 & Completed \\
\hline NCT00663832 & & I & CRPC (+docetaxel and prednisone) & 44 & Completed \\
\hline NCT00493766 & & I & CRPC (+docetaxel and prednisone) & 16 & Terminated \\
\hline NCT00419536 & & I & CRPC (+docetaxel and prednisone) & 108 & Terminated \\
\hline NCT00330161 & Vorinostat (SAHA, MK0683) & II & Metastatic CRPC & 29 & Completed \\
\hline NCT01174199 & & I & Metastatic CRPC & 13 & Terminated \\
\hline NCT00589472 & & II & Primary prostate cancer (+bicalutamide.) & 19 & Completed \\
\hline
\end{tabular}


Table 2 (continued)

\begin{tabular}{|c|c|c|c|c|c|}
\hline Trial ID & Drug & Phase & Conditions & Patients & Status \\
\hline NCT00565227 & & I & $\begin{array}{l}\text { Non-small-cell lung carcinoma, prostate } \\
\text { cancer, bladder cancer, urothelial carcinoma }\end{array}$ & 12 & Terminated \\
\hline NCT00511576 & Mocetinostat (MGCD0103) & I & $\begin{array}{l}\text { Breast cancer, lung cancer, prostate cancer, } \\
\text { gastric cancer (+docetaxel) }\end{array}$ & 54 & Terminated \\
\hline NCT00020579 & Entinostat (MS-275) & I & Advanced solid tumors, lymphoma & 75 & Completed \\
\hline NCT00413075 & Belinostat (PXD101) & I & Advanced solid tumors, lymphoma & 121 & Completed \\
\hline NCT00413322 & & I & Advanced solid tumors (+5-fluorouracil) & 35 & Completed \\
\hline
\end{tabular}

prostate cancer progression. This $\mathrm{H} 3 \mathrm{~K} 4 \mathrm{me} 2-3$ epigenetic reader has been reported mutated in $43 \%$ of Gleason 7 or higher prostate cancer tumors, associated with ETS gene fusion negative status [121] and its loss related with prostate cancer aggressiveness [50] and DNA repair defects, hence sensitizing tumor cells to PARP inhibitors [51]. More recently, Zhao and colleagues at the DePinho laboratory have demonstrated in PTEN null prostate tumors that CHD1 depletion dramatically suppressed cell proliferation, survival, and tumorigenic potential by activating the pro-tumorigenic $\mathrm{TNF}-\mathrm{NF}-\mathrm{KB}$ gene network [122].

\section{Pioneer Factors in Prostate Cancer Progression}

Different from other DNA bound proteins and transcription factors, pioneer factors can access their targets in nucleosomes and in highly compacted chromatin regions, facilitating chromatin accessibility and the recruitment of additional TFs and co-TF and the transcriptional machinery [123]. Among paradigmatic pioneering factors are some of the members of the GATA and FoxA gene families, known mainly for their key role as chromatin-factors during early development [124-127].

The best-known pioneering factor for its role in prostate cancer is FOXA1. Through the interaction and recruitment of AR to chromatin site, FoxA1 defines and controls the AR cistrome resulting in context-dependent positive or negative regulation [52, 55, 128, 129]. In particular, because FOXA1 activity on chromatin results in increased accessibility [52] and increased chromatin-bound AR, high FOXA1 expression leads to a restricted AR cistrome regulation [53].

GATA genes, and GATA2 in particular, have proved to be crucial for prostate development via modulating AR function [54, 55]. However, despite the role is comparable to that of FoxA1, the mechanisms have shown to be quite different. GATA2 depletion did not seem to have a reprogramming effect on AR binding sites and in fact correlated with a downregulation in AR expression. Accordingly, GATA2 activity in human prostate cancer is strongly associated to AR levels and is hence considered a prostate cancer oncogene. Provocatively, it was found that FOXA1 also has the potential to reprogram GATA2 and act as a pioneering effect for both AR and GATA2, suggesting that FOXA1 regulates a transcriptional network that controls AR-mediated gene expression in prostate cancer [53].

\section{Lineage Plasticity in Prostate Cancer Stem Cells}

Aside from their ability to induce pluripotency, the Yamanaka factors (OCT4, SOX2, KLF4, and c-MYC) [130], and other reprograming factors like NANOG or LIN28, have been widely implicated in tumorigenesis in various cancers including the prostate.

SOX2 is required for survival, pluripotency, clonogenicity, and self-renewal of ESCs. A relationship between SOX2 overexpression in tumorigenesis has been established in different types of cancer, including prostate [56] and its expression linked to tumor grade [58]. SOX2 is an epigenetic reprogramming factor and oncogene shown to regulate androgen-independent CRPC proliferation and evasion of apoptosis [57, 58] and to promote tumor metastasis by inducing EMT [59]. Further evidence suggests that SOX2 promotes self-renewal of the CSCs population by acting downstream of EGFR [131]. Importantly, in the recent years, SOX2 activity has been tightly associated to neuroendocrine transdifferentiation from prostate adenocarcinoma cells and the subsequent androgen independence of neuroendocrine prostate cancer phenotypes (NEPC). While the exact mechanisms remain unclear, substantial progress was made over the last couple of years. In particular, Russo and colleagues showed that SOX2 
was expressed in NEPC murine models [60] whereas others found its expression restricted to NEPC areas of advanced human prostate cancer [61]. Recent studies by Bishop and collaborators at the Zoubeidi laboratory have shown that SOX2 is transcriptionally regulated by neural transcription factor BRN2 [132••], which in turn is negatively suppressed by the AR, hence revealing an AR-dependent suppression of cell differentiation toward a neuroendocrine AR-independent phenotype. Additional support to the central role of SOX2 in the emergence of NEPC and AR-independence after Enzalutamide treatment came from studies at the $\mathrm{Ku}$ and $\mathrm{Mu}$ and collaborators at the Sawyers and Goodrich laboratories $[62 \bullet \cdot, 63 \bullet \cdot]$.

c-MYC (MYC) is a well-known oncogene proposed as a marker of disease progression in prostate cancer [133] and associated with prostate cancer recurrence and poor prognosis [134]. MYC activation cooperates with loss of PTEN to drive prostate cancer progression [135] and metastasis [136]. MYC proteins also drive epigenetic activation of gene expression in prostate cancer; the PRC2 member EZH2 is directly upregulated by MYC [137] and MYCN, which was shown to be a driver of NEPC [66] by inducing an EZH2-mediated transcriptional program [64]. Additionally, MYC expression was found to be regulated by the histone demethylase JMJD1A, controlling proliferation and survival of prostate cancer cells [138]. MYC also regulates the expression of histone demethylases PHF8 and KDMA3 in NEPC and CRPC [29]. Interestingly, while AR signaling in the normal prostate represses MYC expression, its expression is stimulated by AR during tumorigenesis, $[139,140]$. It was also recently reported that MYC overexpression deregulates the AR transcriptional program by altering AR chromatin occupancy and $\mathrm{H} 3 \mathrm{~K} 4 \mathrm{me} 1$ and $\mathrm{H} 3 \mathrm{~K} 27 \mathrm{me} 3$ marks distribution, antagonizing clinically relevant AR target genes such as PSA [65].

\section{Oncogenic Pathways Involved in Epigenetic Regulations}

Together with the AR, the oncogenic pathways most frequently altered in prostate cancer onset and progression are the RB, $\mathrm{PI} 3 \mathrm{~K} / \mathrm{AKT}$, and Ras/Raf pathways due to mutations in several members [72]. While the Ras/Raf pathway is activated in $43 \%$ of primary and $90 \%$ of metastatic prostate cancer, the triggering mechanisms remain to be fully understood. The Whitte laboratory demonstrated a synergistic interaction between Ras pathway activation and AR signaling that leads to elevated EZH2 expression and expand prostate cancer progenitor cells in vivo. It has been long suggested that this pathway is a major contributor of aggressiveness via the activation of EMT transcriptional programs. Nolan and colleagues proposed a model in which the secreted extracellular protein Hsp90 initiates ERK signaling and leads to the recruitment of EZH2 to the E-cadherin promoter and repression of E-cadherin expression, driving epithelial to mesenchymal transition (EMT) and invasion in prostate cancer cells [67]. Additionally, DAB2IP (disabled homolog 2 interacting protein) is a tumor suppressor Ras-GAP that negatively controls Ras-dependent mitogenic signals and modulates TNF $\alpha / \mathrm{NF}-\mathrm{kB}, \mathrm{WNT} / \beta$-catenin, PI3K/AKT, and androgen receptors pathways [68-70]. EZH2-induced DAB2IP silencing activates Ras and NFkappaB and triggers metastasis [141, 142]. Data from our laboratory showed that concomitant activation of the PI3K and MAPk pathways in mice results in highly aggressive and fully metastatic tumors that are inherently castration resistant $[143,144]$. Interestingly, by targeting the PI3K/MAPk pathways with small molecules in vivo, we demonstrated that the drug response network was highly enriched in epigenetic modulators, including SUV39H1, WHSC1, TOP2A, or UHRF1 [145], suggesting that epigenetic control of gene expression plays a central role in the aggressive phenotype imposed by the activation of Ras signaling. Accordingly, we have found that a core signature of chromatin modifiers and DNMTs drive the cancer cell intrinsic mechanisms of metastasis and CRPC (unpublished).

The retinoblastoma tumor suppressor gene RB1 is more commonly loss in metastatic and antiandrogen resistant prostate cancer (74\% of cases) and NEPC (90\% of cases) [71] than it is in primary tumors (34\% of cases) [72]. It has been recently described an activity of $\mathrm{Rb} 1$ in the epigenetic regulation of expression, since RB1 directly repress the expression of Sox 2 and Ezh2. Consequently, Rb1 loss in prostate cancer lead to EZH2 and Sox 2 increase and gene expression widespread changes that leads toward a stem cell-like state that would facilitate the onset of metastasis, neuroendocrine transdifferentiation, and the acquisition of ADT resistance. The authors show that Ezh2 inhibition restores enzalutamide sensitivity in NEPC variants and recurrent prostate cancer cells by opposing lineage transformation [63・•]. Furthermore, mutations in TP53 and RB1 tumor suppressor genes can promote a cellular plasticity state mediated by increased expression of SOX2 that, when it is compromised with antiandrogen therapy promotes resistance through lineage switching [62・•]. It has also recently been shown that the Hedgehog (HH) signaling pathway and SOX2 co-operate in androgen-independent prostate cancer to promote carcinogenesis [146].

The PTEN/PI3K/AKT pathway is altered in $42 \%$ of primary and $100 \%$ of metastatic cases; loss of PTEN and activation of the PI3K/AKT signaling pathway are hallmarks of prostate cancer, and cooperate with the activation of the RAS/MAPK pathway to promote EMT and metastatic CRPC development. 
Epigenetically, it has also been shown that PTEN depletion contributes to a switch from a global H3K27 acetylatilation to H3K27 trimethylation, resulting in increased expression of EZH2 and decrease of the target genes DAB2PI together with negative regulator of cell growth $\mathrm{p} 27^{\mathrm{KIP} 1}$ and $\mathrm{p} 21^{\mathrm{CIP} 1}$ [147]. As mentioned above, increased AKT activity phosphorylates NSD2 at S172, preventing its degradation by CRL4 ${ }^{\mathrm{Cd} 2}$ E3 ligase, hence leading to its stabilization, which in turn upregulates RICTOR (mTORC2). This results in further enhancement of AKT signaling in a AKT/NSD2/mTORC2 positive feedback loop that sustains AKT signaling $[1 \bullet \bullet]$.

Constitutive activation of TGF- $\beta$ signaling is a wellrecognized mechanism for induction of EMT and prostate cancer metastasis development. TGF- $\beta 1$-induced EMT in prostate cancer is mediated by the histone methyltransferase RbBP5. RbBP5 is a conserved component of the COMPASS/-like complex, which catalyzes the trimethylation of histone $\mathrm{H} 3$ lysine 4 that is considered an epigenetic mark of actively transcribed genes. RbBP5 activity is in turn modulated by the binding of SMAD2/3, a downstream signaling factor to the TGF-beta pathway, to the Snail promoter [148]. Snail activates the EMT process by inhibiting transcription of E-cadherin via the recruitment to its promoter of the polycomb repressive complex 2 (PRC2) and the histone methylstranferase G9a, leading to repressive H3K27 and H3K9 methylation $[149,150]$. An interesting new perspective was provided recently linking ERG signaling with TGF- $\beta$. Data suggest that ERG regulates the transcription of the transcription factor SOX 4 and together they cooperate in TGF- $\beta 1$-induced EMT of prostate cancer cells [151]. This is not surprising taking into account that the oncogenic role of SOX 4 has been proposed in several other tumor types. In particular, SOX4 regulates EZH2 expression and chromating remodeling, and is a key component of the PI3K/AKT pathway in prostate cancer. In fact, SOX4 inhibition reduces AKT and $\beta$-catenin pathways activation and decreases prostate cancer invasiveness through positive feedback loop between SOX4 and PI3K-AKT-mTOR [152].

Finally, a tyrosine kinase, namely ACK1, has been found to link oncogenic signaling with epigenetic regulation. ACK1 was found upregulated in primary PCa and CRPC $[72,73]$, correlated with poor prognosis and reported to interact with AR to drive ADT resistance and CRPC growth [74]. A recent study demostrates that ACK1 regulates transcription of $A R$ and AR-v7 via epigenetic regulation. In particular, ACK1 would phosphorylate histone H4 upstream of the AR transcription start site, recruiting the WRD5/MLL2 complex, therefore mediating H3K4 trymethylation and transcriptional activation. Inhibition of ACK1 with a small molecule inhibitor confirms that this epigenetic activity is required to maintain AR transcription and CRPC tumor growth [153].

\section{Drug Development on Epigenetic Regulators as Therapeutic Targets}

Mounting evidence from basic and preclinical investigations suggest that targeting key components of the epigenetic machinery will have clinical benefit for cancer patients including prostate cancer ones. Yet, clinical development for those therapies is still very limited. On the one hand, this may be partly due to the inherent difficulty in targeting nuclear effector mechanisms. On the other hand, the fact that most epigenetic master regulators exert their functions over an extensive transcriptional network in a context-dependent manner makes it particularly challenging to achieve cancer cell specificity, thus resulting in significant toxicity. Despite these limitations, a number of drugs are currently in clinical trials at different phases, being BET bromodomain inhibitors, HMT/HDMT inhibitors, DNMT inhibitors, and HDAC inhibitors the focus of most intense drug development efforts. Table 2 summarizes the most relevant ongoing or recently completed clinical trials involving epigenetic drugs.

\section{Conclusion}

In view of the accumulated evidenced supporting the key role of the dysregulated epigenome to prostate cancer onset and progression, three mechanisms emerge as the most significant contributors. First, a number of alterations in epigenetic master regulators result in enhanced transcriptional activity and pro-oncogenic role of the Androgen Receptor signaling. This is largely mediated by either remodeling of the chromatin to facilitate AR binding and assembly of the transcriptional complex and posttranslational modifications in the AR itself or essential co-factors resulting in gain of function features. Secondly, the aberrant activation of transcriptional programs tightly associated to developmental pathways and stem features, either via alterations in pioneering factors or pluripotency master regulators, contributes to the acquisition of treatment-resistant phenotypes that are highly aggressive. Finally, a significant number of alterations in epigenetic master regulators also result in the activation of oncogenic signaling pathways that contribute to the aggressiveness and androgen independence in advanced prostate tumors. In summary, the epigenome is emerging as an attractive and plausible target for anticancer therapy in general and prostate cancer in particular. While drug development is still limited, and faces inherent challenges associated with the unique nature of these targets, it seems evident that efficacy of such treatments will be maximized in combination with standard of care treatments for which most lethal prostate cancer ultimately develop resistant mechanism. 
Acknowledgements This research is supported by funding from the Spanish Ministry of Economy, Industry and Competitiveness (MINECO), which is part of the State Research Agency, through the projects PI16/01070 and CP15/00090. We also acknowledge the support from the European Association of Urology Research Foundation (EAURF/407003/XH), and the Fundacion BBVA-Young Investigator Award. We thank CERCA Program / Generalitat de Catalunya for the institutional support.

\section{Compliance with Ethical Standards}

Conflict of Interest Katia Ruggero, Sonia Farran-Matas, Adrian Martinez-Tebar, and Alvaro Aytes declare no conflicts of interest.

Human and Animal Rights and Informed Consent This article does not contain any studies with human or animal subjects performed by any of the authors.

Open Access This article is distributed under the terms of the Creative Commons Attribution 4.0 International License (http:// creativecommons.org/licenses/by/4.0/), which permits unrestricted use, distribution, and reproduction in any medium, provided you give appropriate credit to the original author(s) and the source, provide a link to the Creative Commons license, and indicate if changes were made.

\section{References}

Papers of particular interest, published recently, have been highlighted as:

- Of importance

•- Of major importance

1.• Li N, Xue W, Yuan H, Dong B, Ding Y, Liu Y, et al. AKTmediated stabilization of histone methyltransferase WHSC1 promotes prostate cancer metastasis. J Clin Invest. 2017;127(4): 1284-302. This work demonstrates that NSD2 is activated in PTEN null tumors by the AKT pathway and that its expression is required for metastatic progression.

2. Ezponda T, Popovic R, Shah MY, Martinez-Garcia E, Zheng Y, Min DJ, et al. The histone methyltransferase MMSET/WHSC1 activates TWIST1 to promote an epithelial-mesenchymal transition and invasive properties of prostate cancer. Oncogene. 2013;32(23):2882-90.

3. Asangani IA, Ateeq B, Cao Q, Dodson L, Pandhi M, Kunju LP, et al. Characterization of the EZH2-MMSET histone methyltransferase regulatory axis in cancer. Mol Cell. 2013;49(1):80-93.

4. Yang YA, Yu J. EZH2, an epigenetic driver of prostate cancer. Protein Cell. 2013;4(5):331-41.

5. Wu C, Jin X, Yang J, Yang Y, He Y, Ding L, et al. Inhibition of EZH2 by chemo- and radiotherapy agents and small molecule inhibitors induces cell death in castration-resistant prostate cancer. Oncotarget. 2016;7(3):3440-52.

6. Yu T, Wang C, Yang J, Guo Y, Wu Y, Li X. Metformin inhibits SUV39H1-mediated migration of prostate cancer cells. Oncogene. 2017;6(5):):28.

7. Li Q, Li Y, Wang Y, Cui Z, Gong L, Qu Z, et al. Quantitative proteomic study of human prostate cancer cells with different metastatic potentials. Int J Oncol. 2016;48(4):1437-46.

8. Askew EB, Bai S, Parris AB, Minges JT, Wilson EM. Androgen receptor regulation by histone methyltransferase suppressor of variegation 3-9 homolog 2 and melanoma antigen-A11. Mol Cell Endocrinol. 2017;443:42-51.
9. Vieira FQ, Costa-Pinheiro P, Almeida-Rios D, Graca I, MonteiroReis S, Simoes-Sousa S, et al. SMYD3 contributes to a more aggressive phenotype of prostate cancer and targets cyclin D2 through H4K20me3. Oncotarget. 2015;6(15):13644-57.

10. Huang L, Xu AM. SET and MYND domain containing protein 3 in cancer. Am J Transl Res. 2017;9(1):1-14.

11. Stopa N, Krebs JE, Shechter D. The PRMT5 arginine methyltransferase: many roles in development, cancer and beyond. Cell Mol Life Sci. 2015;72(11):2041-59.

12. Mounir Z, Korn JM, Westerling T, Lin F, Kirby CA, Schirle M, et al. ERG signaling in prostate cancer is driven through PRMT5dependent methylation of the Androgen Receptor. Elife. 2016;16(5):13964. This paper links for the first time epigenetically driven posttranslational modifications in the $A R$ and ERG transcriptional expression.

13. Deng X, Shao G, Zhang HT, Li C, Zhang D, Cheng L, et al. Protein arginine methyltransferase 5 functions as an epigenetic activator of the androgen receptor to promote prostate cancer cell growth. Oncogene. 2017;36(9):1223-31.

14.• Metzger E, Wissmann M, Yin N, Muller JM, Schneider R, Peters $\mathrm{AH}$, et al. LSD1 demethylates repressive histone marks to promote androgen-receptor-dependent transcription. Nature. 2005;437(7057):436-9. This paper links demethylation of a repressive histone mark with androgen-receptor-dependent gene activation.

15. Cai C, He HH, Chen S, Coleman I, Wang H, Fang Z, et al. Androgen receptor gene expression in prostate cancer is directly suppressed by the androgen receptor through recruitment of lysine-specific demethylase 1. Cancer Cell. 2011;20(4):457-71.

16. Liang Y, Ahmed M, Guo H, Soares F, Hua JT, Gao S, et al. LSD1mediated epigenetic reprogramming drives CENPE expression and prostate cancer progression. Cancer Res. 2017;77(20):5479 90. This study shows that LSD1-mediated epigenetic reprogramming drives CRPC and was associated with the activation of CENPE and other cell-cycle genes.

17. Xiang Y, Zhu Z, Han G, Ye X, Xu B, Peng Z, et al. JARID1B is a histone $\mathrm{H} 3$ lysine 4 demethylase up-regulated in prostate cancer. Proc Natl Acad Sci U S A. 2007;104(49):19226-31.

18. Lu W, Liu S, Li B, Xie Y, Adhiambo C, Yang Q, et al. SKP2 inactivation suppresses prostate tumorigenesis by mediating JARID1B ubiquitination. Oncotarget. 2015;6(2):771-88.

19. Stein J, Majores M, Rohde M, Lim S, Schneider S, Krappe E, et al. $\mathrm{KDM} 5 \mathrm{C}$ is overexpressed in prostate cancer and is a prognostic marker for prostate-specific antigen-relapse following radical prostatectomy. Am J Pathol. 2014;184(9):2430-7.

20. Li N, Dhar SS, Chen TY, Kan PY, Wei Y, Kim JH, et al. JARID1D is a suppressor and prognostic marker of prostate cancer invasion and metastasis. Cancer Res. 2016;76(4):831-43.

21. Komura K, Jeong SH, Hinohara K, Qu F, Wang X, Hiraki M, et al. Resistance to docetaxel in prostate cancer is associated with androgen receptor activation and loss of KDM5D expression. Proc Natl Acad Sci U S A. 2016;113(22):6259-64.

22. Yu L, Wang Y, Huang S, Wang J, Deng Z, Zhang Q, et al. Structural insights into a novel histone demethylase PHF8. Cell Res. 2010;20(2):166-73.

23. Qi HH, Sarkissian M, Hu G-Q, Wang Z, Bhattacharjee A, Gordon DB, et al. Histone H4K20/H3K9 demethylase PHF8 regulates zebrafish brain and craniofacial development. Nature. 2010;466: 503-7.

24. Qiu J, Shi G, Jia Y, Li J, Wu M, Li J, et al. The X-linked mental retardation gene PHF8 is a histone demethylase involved in neuronal differentiation. Cell Res. 2010;20:908-18.

25. Liu W, Tanasa B, Tyurina OV, Zhou TY, Gassmann R, Liu WT, et al. PHF8 mediates histone H4 lysine 20 demethylation events involved in cell cycle progression. Nature. 2010;466(7305):508 12 . 
26. Horton JR, Upadhyay AK, Qi HH, Zhang X, Shi Y, Cheng X. Enzymatic and structural insights for substrate specificity of a family of jumonji histone lysine demethylases. Nat Struct Amp Mol Biol. 2009;17:38.

27. Bjorkman M, Ostling P, Harma V, Virtanen J, Mpindi JP, Rantala $\mathrm{J}$, et al. Systematic knockdown of epigenetic enzymes identifies a novel histone demethylase PHF8 overexpressed in prostate cancer with an impact on cell proliferation, migration and invasion. Oncogene. 2012;31(29):3444-56.

28. Tong D, Liu Q, Liu G, Yuan W, Wang L, Guo Y, et al. The HIF/ PHF8/AR axis promotes prostate cancer progression. Oncogene. 2016;5(12):e283.

29. Maina PK, Shao P, Liu Q, Fazli L, Tyler S, Nasir M, et al. c-MYC drives histone demethylase PHF8 during neuroendocrine differentiation and in castration-resistant prostate cancer. Oncotarget. 2016;7(46):75585-602.

30. Shin S, Janknecht R. Activation of androgen receptor by histone demethylases JMJD2A and JMJD2D. Biochem Biophys Res Commun. 2007;359(3):742-6.

31. Wissmann M, Yin N, Muller JM, Greschik H, Fodor BD, Jenuwein $\mathrm{T}$, et al. Cooperative demethylation by JMJD2C and LSD1 promotes androgen receptor-dependent gene expression. Nat Cell Biol. 2007;9(3):347-53.

32. Yamane K, Toumazou C, Tsukada Y, Erdjument-Bromage H, Tempst P, Wong J, et al. JHDM2A, a JmjC-containing H3K9 demethylase, facilitates transcription activation by androgen receptor. Cell. 2006;125(3):483-95.

33. Wilson S, Fan L, Sahgal N, Qi J, Filipp FV. The histone demethylase KDM3A regulates the transcriptional program of the androgen receptor in prostate cancer cells. Oncotarget. 2017;8(18):30328-43.

34. Coffey K, Rogerson L, Ryan-Munden C, Alkharaif D, Stockley J, Heer R, et al. The lysine demethylase, KDM4B, is a key molecule in androgen receptor signalling and turnover. Nucleic Acids Res. 2013;41(8):4433-46.

35. Xiang Y, Zhu Z, Han G, Lin H, Xu L, Chen CD. JMJD3 is a histone H3K27 demethylase. Cell Res. 2007;17(10):850-7.

36. Chin SP, Dickinson JL, Holloway AF. Epigenetic regulation of prostate cancer. Clin Epigenetics. 2011;2(2):151-69.

37. Lin PC, Giannopoulou EG, Park K, Mosquera JM, Sboner A, Tewari AK, et al. Epigenomic alterations in localized and advanced prostate cancer. Neoplasia. 2013;15(4):373-83.

38. Kang GH, Lee S, Lee HJ, Hwang KS. Aberrant CpG island hypermethylation of multiple genes in prostate cancer and prostatic intraepithelial neoplasia. J Pathol. 2004;202(2):233-40.

39. Mahon KL, Qu W, Devaney J, Paul C, Castillo L, Wykes RJ, et al. Methylated glutathione S-transferase 1 (mGSTP1) is a potential plasma free DNA epigenetic marker of prognosis and response to chemotherapy in castrate-resistant prostate cancer. $\mathrm{Br} \mathrm{J}$ Cancer. 2014;111(9):1802-9.

40. Fu M, Wang C, Reutens AT, Wang J, Angeletti RH, SiconolfiBaez L, et al. p300 and p300/cAMP-response element-binding protein-associated factor acetylate the androgen receptor at sites governing hormone-dependent transactivation. J Biol Chem. 2000;275(27):20853-60.

41. Jin L, Garcia J, Chan E, de la Cruz C, Segal E, Merchant M, et al. Therapeutic targeting of the $\mathrm{CBP} / \mathrm{p} 300$ bromodomain blocks the growth of castration-resistant prostate cancer. Cancer Res. 2017;77(20):5564-75

42. Fu M, Liu M, Sauve AA, Jiao X, Zhang X, Wu X, et al. Hormonal control of androgen receptor function through SIRT1. Mol Cell Biol. 2006;26(21):8122-35.

43. Lavery DN, Bevan CL. Androgen receptor signalling in prostate cancer: the functional consequences of acetylation. J Biomed Biotechnol. 2011;862125(10):28.
44. Damodaran S, Damaschke N, Gawdzik J, Yang B, Shi C, Allen GO, et al. Dysregulation of Sirtuin 2 (SIRT2) and histone H3K18 acetylation pathways associates with adverse prostate cancer outcomes. BMC Cancer. 2017;17(1):874.

45. Asangani IA, Dommeti VL, Wang X, Malik R, Cieslik M, Yang $\mathrm{R}$, et al. Therapeutic targeting of BET bromodomain proteins in castration-resistant prostate cancer. Nature. 2014;510(7504):27882. This study reports that BRD4 physically interacts with high-affinity with the $\mathrm{N}$-terminal domain of AR leading to $A R$ translocation into the nucleus and $A R$ recruitment to target loci, promoting AR activity and expression of AR target genes in CRPC.

46. Shah N, Wang P, Wongvipat J, Karthaus WR, Abida W, Armenia $\mathrm{J}$, et al. Regulation of the glucocorticoid receptor via a BETdependent enhancer drives antiandrogen resistance in prostate cancer. elife. 2017;6

47. Li J, Alyamani M, Zhang A, Chang KH, Berk M, Li Z, et al. Aberrant corticosteroid metabolism in tumor cells enables GR takeover in enzalutamide resistant prostate cancer. elife. 2017;6

48. Dai X, Gan W, Li X, Wang S, Zhang W, Huang L, et al. Prostate cancer-associated SPOP mutations confer resistance to BET inhibitors through stabilization of BRD4. Nat Med. 2017;23(9):106371.

49. Groner AC, Cato L, de Tribolet-Hardy J, Bernasocchi T, Janouskova H, Melchers D, et al. TRIM24 is an oncogenic transcriptional activator in prostate cancer. Cancer Cell. 2016;29(6): 846-58.

50. Rodrigues LU, Rider L, Nieto C, Romero L, Karimpour-Fard A, Loda M, et al. Coordinate loss of MAP3K 7 and CHD1 promotes aggressive prostate cancer. Cancer Res. 2015;75(6):1021-34.

51. Kari V, Mansour WY, Raul SK, Baumgart SJ, Mund A, Grade M, et al. Loss of CHD1 causes DNA repair defects and enhances prostate cancer therapeutic responsiveness. EMBO Rep. 2016;17(11):1609-23.

52. Jin HJ, Zhao JC, Wu L, Kim J, Yu J. Cooperativity and equilibrium with FOXA1 define the androgen receptor transcriptional program. Nat Commun. 2014;5(3972)

53. Zhao JC, Fong KW, Jin HJ, Yang YA, Kim J, Yu J. FOXA1 acts upstream of GATA2 and AR in hormonal regulation of gene expression. Oncogene. 2016;35(33):4335-44.

54. Lupien M, Eeckhoute J, Meyer CA, Wang Q, Zhang Y, Li W, et al. Fox A1 translates epigenetic signatures into enhancer-driven lineage-specific transcription. Cell. 2008;132(6):958-70.

55. Wang Q, Li W, Liu XS, Carroll JS, Jänne OA, Keeton EK, et al. A hierarchical network of transcription factors governs androgen receptor-dependent prostate cancer growth. Mol Cell. 2007;27(3):380-92.

56. Wong OG, Huo Z, Siu MK, Zhang H, Jiang L, Wong ES, et al. Hypermethylation of SOX2 promoter in endometrial carcinogenesis. Obstet Gynecol Int. 2010;10(682504):9.

57. Lin F, Lin P, Zhao D, Chen Y, Xiao L, Qin W, et al. Sox 2 targets cyclinE, p 27 and survivin to regulate androgen-independent human prostate cancer cell proliferation and apoptosis. Cell Prolif. 2012;45(3):207-16.

58. Kregel S, Kiriluk KJ, Rosen AM, Cai Y, Reyes EE, Otto KB, et al. Sox2 is an androgen receptor-repressed gene that promotes castration-resistant prostate cancer. PLoS One. 2013;8(1):11.

59. Li X, Xu Y, Chen Y, Chen S, Jia X, Sun T, et al. SOX2 promotes tumor metastasis by stimulating epithelial-to-mesenchymal transition via regulation of WNT/beta-catenin signal network. Cancer Lett. 2013;336(2):379-89.

60. Russo MV, Esposito S, Tupone MG, Manzoli L, Airoldi I, Pompa $\mathrm{P}$, et al. SOX2 boosts major tumor progression genes in prostate cancer and is a functional biomarker of lymph node metastasis. Oncotarget. 2016;7(11):12372-85. 
61. Esposito S, Russo MV, Airoldi I, Tupone MG, Sorrentino C, Barbarito G, et al. SNAI2/Slug gene is silenced in prostate cancer and regulates neuroendocrine differentiation, metastasissuppressor and pluripotency gene expression. Oncotarget. 2015;6(19):17121-34.

62.• Mu P, Zhang Z, Benelli M, Karthaus WR, Hoover E, Chen CC, et al. SOX2 promotes lineage plasticity and antiandrogen resistance in TP53- and RB1-deficient prostate cancer. Science. 2017;355(6320):84-8. This work demonstrates that lineage plasticity and neuroendocrine differentiation in androgen independence is partly driven by Sox 2 in prostate cancer mouse models carrying loss of function alleles for $\mathrm{p53}$ and $\mathrm{Rb}$ tumor suppressors.

63.• Ku SY, Rosario S, Wang Y, Mu P, Seshadri M, Goodrich ZW, et al. $\mathrm{Rb} 1$ and Trp53 cooperate to suppress prostate cancer lineage plasticity, metastasis, and antiandrogen resistance. Science. 2017;355(6320):78-83. This work shows that Sox2 and Ezh2 mediates suppression of prostate cancer lineage plasticity in Rb1 and p53 null tumours. Ezh2 inhibition restores enzalutamide sensitivity in NEPC variants and recurrent prostate cancer cells by opposing lineage transformation.

64. Dardenne E, Beltran H, Benelli M, Gayvert K, Berger A, Puca L, et al. N-Myc induces an EZH2-mediated transcriptional program driving neuroendocrine prostate Cancer. Cancer Cell. 2016;30(4): 563-77.

65. Barfeld SJ, Urbanucci A, Itkonen HM, Fazli L, Hicks JL, Thiede B, et al. C-Myc Antagonises the transcriptional activity of the androgen receptor in prostate cancer affecting key gene networks. EBioMedicine. 2017;18:83-93.

66. Lee JK, Phillips JW, Smith BA, Park JW, Stoyanova T, McCaffrey $\mathrm{EF}$, et al. N-Myc drives neuroendocrine prostate cancer initiated from human prostate epithelial cells. Cancer Cell. 2016;29(4): 536- 47.

67. Nolan KD, Franco OE, Hance MW, Hayward SW, Isaacs JS. Tumor-secreted Hsp90 subverts polycomb function to drive prostate tumor growth and invasion. J Biol Chem. 2015;290(13): 8271-82.

68. Bellazzo A, Di Minin G, Collavin L. Block one, unleash a hundred. Mechanisms of DAB2IP inactivation in cancer. Cell Death Differ. 2017;24(1):15-25.

69. Wu K, Liu J, Tseng SF, Gore C, Ning Z, Sharifi N, et al. The role of DAB2IP in androgen receptor activation during prostate cancer progression. Oncogene. 2014;33(15):1954-63.

70. Tsai YS, Lai CL, Lai CH, Chang KH, Wu K, Tseng SF, et al. The role of homeostatic regulation between tumor suppressor DAB2IP and oncogenic Skp2 in prostate cancer growth. Oncotarget. 2014;5(15):6425-36

71. Tan HL, Sood A, Rahimi HA, Wang W, Gupta N, Hicks J, et al. $\mathrm{Rb}$ loss is characteristic of prostatic small cell neuroendocrine carcinoma. Clin Cancer Res. 2014;20(4):890-903.

72. Taylor BS, Schultz N, Hieronymus H, Gopalan A, Xiao Y, Carver $\mathrm{BS}$, et al. Integrative genomic profiling of human prostate cancer. Cancer Cell. 2010;18(1):11-22.

73. van der Horst EH, Degenhardt YY, Strelow A, Slavin A, Chinn L, Orf J, et al. Metastatic properties and genomic amplification of the tyrosine kinase gene ACK1. Proc Natl Acad Sci U S A. 2005;102(44):15901-6.

74. Mahajan NP, Liu Y, Majumder S, Warren MR, Parker CE, Mohler JL, et al. Activated Cdc42-associated kinase Ack1 promotes prostate cancer progression via androgen receptor tyrosine phosphorylation. Proc Natl Acad Sci U S A. 2007;104(20):8438-43.

75. Nelson WG, De Marzo AM, Yegnasubramanian S. Epigenetic alterations in human prostate cancers. Endocrinology. 2009;150(9):3991-4002.
76. Suzuki H, Ueda T, Ichikawa T, Ito H. Androgen receptor involvement in the progression of prostate cancer. Endocr Relat Cancer 2003;10(2):209-16.

77. Suzuki H, Freije D, Nusskern DR, Okami K, Cairns P, Sidransky $\mathrm{D}$, et al. Interfocal heterogeneity of PTEN/MMAC1 gene alterations in multiple metastatic prostate cancer tissues. Cancer Res. 1998;58(2):204-9.

78. Jarrard DF, Bova GS, Ewing CM, Pin SS, Nguyen SH, Baylin SB, et al. Deletional, mutational, and methylation analyses of CDKN2 (p16/MTS1) in primary and metastatic prostate cancer. Genes Chromosomes Cancer. 1997;19(2):90-6.

79. Pakneshan P, Xing RH, Rabbani SA. Methylation status of uPA promoter as a molecular mechanism regulating prostate cancer invasion and growth in vitro and in vivo. FASEB J. 2003;17(9): 1081-8.

80. Ashour N, Angulo JC, Andres G, Alelu R, Gonzalez-Corpas A, Toledo MV, et al. A DNA hypermethylation profile reveals new potential biomarkers for prostate cancer diagnosis and prognosis. Prostate. 2014;74(12):1171-82.

81. Coffey K, Rogerson L, Ryan-Munden C, Alkharaif D, Stockley J, Heer R, et al. The lysine demethylase, KDM4B, is a key molecule in androgen receptor signalling and turnover. Nucleic Acids Res. 2013;41(8):4433-46.

82. Hayami S, Kelly JD, Cho HS, Yoshimatsu M, Unoki M, Tsunoda $\mathrm{T}$, et al. Overexpression of LSD1 contributes to human carcinogenesis through chromatin regulation in various cancers. Int $\mathrm{J}$ Cancer. 2011;128(3):574-86.

83. Kahl P, Gullotti L, Heukamp LC, Wolf S, Friedrichs N, Vorreuther $\mathrm{R}$, et al. Androgen receptor coactivators lysine-specific histone demethylase 1 and four and a half LIM domain protein 2 predict risk of prostate cancer recurrence. Cancer Res. 2006;66(23): 11341-7.

84. Battaglia S, Karasik E, Gillard B, Williams J, Winchester T, Moser MT, et al. LSD1 dual function in mediating epigenetic corruption of the vitamin D signaling in prostate cancer. Clin Epigenetics. 2017;9(82):017-0382.

85. Li Y, Trojer P, Xu CF, Cheung P, Kuo A, Drury WJ, 3rd, et al. The target of the NSD family of histone lysine methyltransferases depends on the nature of the substrate. J Biol Chem 2009; 284(49): 34283-34295.

86. Keats JJ, Maxwell CA, Taylor BJ, Hendzel MJ, Chesi M, Bergsagel PL, et al. Overexpression of transcripts originating from the MMSET locus characterizes all $\mathrm{t}(4 ; 14)(\mathrm{p} 16 ; \mathrm{q} 32)$-positive multiple myeloma patients. Blood. 2005;105(10):4060-9.

87. Yang P, Guo L, Duan ZJ, Tepper CG, Xue L, Chen X, et al. Histone methyltransferase NSD2/MMSET mediates constitutive NF-kappaB signaling for cancer cell proliferation, survival, and tumor growth via a feed-forward loop. Mol Cell Biol. 2012;32(15):3121-31.

88. Kang HB, Choi Y, Lee JM, Choi KC, Kim HC, Yoo JY, et al. The histone methyltransferase, NSD2, enhances androgen receptormediated transcription. FEBS Lett. 2009;583(12):1880-6.

89. Nalla AK, Williams TF, Collins CP, Rae DT, Trobridge GD. Lentiviral vector-mediated insertional mutagenesis screen identifies genes that influence androgen independent prostate cancer progression and predict clinical outcome. Mol Carcinog. 2016;55(11):1761-71.

90. Shi Y, Lan F, Matson C, Mulligan P, Whetstine JR, Cole PA, et al. Histone demethylation mediated by the nuclear amine oxidase homolog LSD1. Cell. 2004;119(7):941-53.

91. Metzger E, Yin N, Wissmann M, Kunowska N, Fischer K, Friedrichs N, et al. Phosphorylation of histone $\mathrm{H} 3$ at threonine 11 establishes a novel chromatin mark for transcriptional regulation. Nat Cell Biol. 2008;10(1):53-60.

92. Jia L, Berman BP, Jariwala U, Yan X, Cogan JP, Walters A, et al. Genomic androgen receptor-occupied regions with different 
functions, defined by histone acetylation, coregulators and transcriptional capacity. PLoS One. 2008;3(11):10.

93. Jia L, Shen HC, Wantroba M, Khalid O, Liang G, Wang Q, et al. Locus-wide chromatin remodeling and enhanced androgen receptor-mediated transcription in recurrent prostate tumor cells. Mol Cell Biol. 2006;26(19):7331-41.

94. Lasko LM, Jakob CG, Edalji RP, Qiu W, Montgomery D, Digiammarino EL, et al. Discovery of a selective catalytic p300/ CBP inhibitor that targets lineage-specific tumours. Nature. 2017;550(7674):128-32.

95. Valdes-Mora F, Gould CM, Colino-Sanguino Y, Qu W, Song JZ, Taylor KM, et al. Acetylated histone variant H2A.Z is involved in the activation of neo-enhancers in prostate cancer. Nat Commun. 2017;8(1):1346. This study highlights the important role of histone acetylation in prostate cancer beyond active promoters via activation of $A R$ associated enhancers and the increase in chromatin accessibility

96. Ruscetti M, Dadashian EL, Guo W, Quach B, Mulholland DJ, Park JW, et al. HDAC inhibition impedes epithelialmesenchymal plasticity and suppresses metastatic, castrationresistant prostate cancer. Oncogene. 2016;35(29):3781-95.

97. Di Croce L, Helin K. Transcriptional regulation by polycomb group proteins. Nat Struct Mol Biol. 2013;20(10):1147-55.

98. Melling N, Thomsen E, Tsourlakis MC, Kluth M, Hube-Magg C, Minner S, et al. Overexpression of enhancer of zeste homolog 2 (EZH2) characterizes an aggressive subset of prostate cancers and predicts patient prognosis independently from pre- and postoperatively assessed clinicopathological parameters. Carcinogenesis. 2015;36(11):1333-40.

99. Lee TI, Jenner RG, Boyer LA, Guenther MG, Levine SS, Kumar RM, et al. Control of developmental regulators by Polycomb in human embryonic stem cells. Cell. 2006;125(2):301-13.

100. Liu L, Xu Z, Zhong L, Wang H, Jiang S, Long Q, et al. Enhancer of zeste homolog 2 (EZH2) promotes tumour cell migration and invasion via epigenetic repression of E-cadherin in renal cell carcinoma. BJU Int. 2016;117(2):351-62.

101. $\mathrm{Xu} \mathrm{H}, \mathrm{Xu} \mathrm{K}, \mathrm{He} \mathrm{HH}$, Zang C, Chen $\mathrm{CH}$, Chen $\mathrm{Y}$, et al. Integrative analysis reveals the transcriptional collaboration between EZH2 and $\mathrm{E} 2 \mathrm{~F} 1$ in the regulation of cancer-related gene expression. Mol Cancer Res. 2016;14(2):163-72.

102. Cha TL, Zhou BP, Xia W, Wu Y, Yang CC, Chen CT, et al. Aktmediated phosphorylation of EZH2 suppresses methylation of lysine 27 in histone H3. Science. 2005;310(5746):306-10.

103.• Xu K, Wu ZJ, Groner AC, He HH, Cai C, Lis RT, et al. EZH2 oncogenic activity in castration-resistant prostate cancer cells is Polycomb-independent. Science. 2012;338(6113):1465-9. This paper provides compelling evidence that the oncogenic role of Ezh2 in CRPC is partly independent of its repressive function and acts via coactivator functions with key transcription factors including AR

104. Labbe DP, Sweeney CJ, Brown M, Galbo P, Rosario S, Wadosky $\mathrm{KM}$, et al. TOP2A and EZH2 provide early detection of an aggressive prostate cancer subgroup. Clin Cancer Res. 2017;23(22): 7072-83.

105. Urbanucci A, Mills IG. Bromodomain-containing proteins in prostate cancer. Mol Cell Endocrinol. 2017;

106. Fujisawa T, Filippakopoulos P. Functions of bromodomaincontaining proteins and their roles in homeostasis and cancer. Nat Rev Mol Cell Biol. 2017;18(4):246-62.

107.• Loven J, Hoke HA, Lin CY, Lau A, Orlando DA, Vakoc CR, et al. Selective inhibition of tumor oncogenes by disruption of superenhancers. Cell 2013; 153(2):320-334.

108.• Whyte WA, Orlando DA, Hnisz D, Abraham BJ, Lin CY, Kagey $\mathrm{MH}$, et al. Master transcription factors and mediator establish super-enhancers at key cell identity genes. Cell. 2013;153(2): $307-19$. This two papers provide evidence that disruption of enhancers and superenhancers through BET bromodomain inhibition is a promising therapeutic option in cancer and highlight the key role of this epigenetic master regulator in cancer progression

109. Jang MK, Mochizuki K, Zhou M, Jeong HS, Brady JN, Ozato K. The bromodomain protein Brd4 is a positive regulatory component of P-TEFb and stimulates RNA polymerase II-dependent transcription. Mol Cell. 2005;19(4):523-34.

110. Zuber V, Bettella F, Witoelar A, Andreassen OA, Mills IG, Urbanucci A. Bromodomain protein 4 discriminates tissuespecific super-enhancers containing disease-specific susceptibility loci in prostate and breast cancer. BMC Genomics. 2017;18(1): 270.

111. Faivre EJ, Wilcox D, Lin X, Hessler P, Torrent M, He W, et al. Exploitation of castration-resistant prostate cancer transcription factor dependencies by the novel BET inhibitor ABBV-075. Mol Cancer Res. 2017;15(1):35-44.

112. Asangani IA, Wilder-Romans K, Dommeti VL, Krishnamurthy PM, Apel IJ, Escara-Wilke J, et al. BET Bromodomain inhibitors enhance efficacy and disrupt resistance to AR antagonists in the treatment of prostate cancer. Mol Cancer Res. 2016;14(4):324-31.

113. Arora VK, Schenkein E, Murali R, Subudhi SK, Wongvipat J, Balbas MD, et al. Glucocorticoid receptor confers resistance to antiandrogens by bypassing androgen receptor blockade. Cell. 2013;155(6):1309-22.

114. Blee AM, Liu S, Wang L, Huang H. BET bromodomain-mediated interaction between ERG and BRD4 promotes prostate cancer cell invasion. Oncotarget. 2016;7(25):38319-32.

115. Janouskova H, El Tekle G, Bellini E, Udeshi ND, Rinaldi A, Ulbricht A, et al. Opposing effects of cancer-type-specific SPOP mutants on BET protein degradation and sensitivity to BET inhibitors. Nat Med. 2017;23(9):1046-54.

116. Zhang P, Wang D, Zhao Y, Ren S, Gao K, Ye Z, et al. Intrinsic BET inhibitor resistance in SPOP-mutated prostate cancer is mediated by BET protein stabilization and AKT-mTORC1 activation. Nat Med. 2017;23(9):1055-62.

117. Gupta-Elera G, Garrett AR, Robison RA, O'Neill KL. The role of oxidative stress in prostate cancer. Eur J Cancer Prev. 2012;21(2): 155-62.

118. Hussong M, Borno ST, Kerick M, Wunderlich A, Franz A, Sultmann $\mathrm{H}$, et al. The bromodomain protein BRD4 regulates the KEAP1/NRF2-dependent oxidative stress response. Cell Death Dis. 2014;5:e1195.

119. Theurillat JP, Udeshi ND, Errington WJ, Svinkina T, Baca SC, Pop M, et al. Prostate cancer. Ubiquitylome analysis identifies dysregulation of effector substrates in SPOP-mutant prostate cancer. Science. 2014;346(6205):85-9.

120. Kikuchi M, Okumura F, Tsukiyama T, Watanabe M, Miyajima N, Tanaka J, et al. TRIM24 mediates ligand-dependent activation of androgen receptor and is repressed by a bromodomain-containing protein, BRD7, in prostate cancer cells. Biochim Biophys Acta. 2009;1793(12):1828-36.

121. Grasso CS, Wu YM, Robinson DR, Cao X, Dhanasekaran SM, Khan AP, et al. The mutational landscape of lethal castrationresistant prostate cancer. Nature. 2012;487(7406):239-43.

122. Zhao D, Lu X, Wang G, Lan Z, Liao W, Li J, et al. Synthetic essentiality of chromatin remodelling factor CHD1 in PTENdeficient cancer. Nature. 2017;542(7642):484-8.

123. Zaret KS, Carroll JS. Pioneer transcription factors: establishing competence for gene expression. Genes Dev. 2011;25(21):222741.

124. Lee CS, Friedman JR, Fulmer JT, Kaestner KH. The initiation of liver development is dependent on Foxa transcription factors. Nature. 2005;435(7044):944-7. 
125. Watt AJ, Zhao R, Li J, Duncan SA. Development of the mammalian liver and ventral pancreas is dependent on GATA4. BMC Dev Biol. 2007;7(1):37.

126. Zhao R, Watt AJ, Li J, Luebke-Wheeler J, Morrisey EE, Duncan SA. GATA6 is essential for embryonic development of the liver but dispensable for early heart formation. Mol Cell Biol. 2005;25(7):2622-31.

127. Holtzinger A, Evans T. Gata4 regulates the formation of multiple organs. Development. 2005;132(17):4005-14.

128. Wang Q, Li W, Zhang Y, Yuan X, Xu K, Yu J, et al. Androgen receptor regulates a distinct transcription program in androgenindependent prostate cancer. Cell. 2009;138(2):245-56.

129. Wang D, Garcia-Bassets I, Benner C, Li W, Su X, Zhou Y, et al. Reprogramming transcription by distinct classes of enhancers functionally defined by eRNA. Nature. 2011;474(7351):390-4.

130. Takahashi K, Tanabe K, Ohnuki M, Narita M, Ichisaka T, Tomoda $\mathrm{K}$, et al. Induction of pluripotent stem cells from adult human fibroblasts by defined factors. Cell. 2007;131(5):861-72.

131. Rybak AP, Tang D. SOX2 plays a critical role in EGFR-mediated self-renewal of human prostate cancer stem-like cells. Cell Signal. 2013;25(12):2734-42.

132.• Bishop JL, Thaper D, Vahid S, Davies A, Ketola K, Kuruma H, et al. The master neural transcription factor BRN2 is an androgen receptor-suppressed driver of neuroendocrine differentiation in prostate cancer. Cancer Discov. 2017;7(1):54-71. This works provides a mechanistic model for neuroendocrine differentiation after AR signaling blockade using patiend-derived models

133. Zeng W, Sun H, Meng F, Liu Z, Xiong J, Zhou S, et al. Nuclear CMYC expression level is associated with disease progression and potentially predictive of two year overall survival in prostate cancer. Int J Clin Exp Pathol. 2015;8(2):1878-88.

134. Rye M, Bertilsson H, Drabløs F, Angelsen A, Bathen T, Tessem M-B. Gene signatures ESC, MYC and ERG-fusion are early markers of a potentially dangerous subtype of prostate cancer2014. 50 p.

135. Kim J, Roh M, Doubinskaia I, Algarroba GN, Eltoum IE, Abdulkadir SA. A mouse model of heterogeneous, c-MYCinitiated prostate cancer with loss of Pten and p53. Oncogene. 2012;31(3):322-32.

136. Hubbard GK, Mutton LN, Khalili M, McMullin RP, Hicks JL, Bianchi-Frias D, et al. Combined MYC activation and Pten loss are sufficient to create genomic instability and lethal metastatic prostate cancer. Cancer Res. 2016;76(2):283-92.

137. Koh CM, Iwata T, Zheng Q, Bethel C, Yegnasubramanian S, De Marzo AM. Myc enforces overexpression of EZH2 in early prostatic neoplasia via transcriptional and post-transcriptional mechanisms. Oncotarget. 2011;2(9):669-83.

138. Fan L, Peng G, Sahgal N, Fazli L, Gleave M, Zhang Y, et al. Regulation of c-Myc expression by the histone demethylase JMJD1A is essential for prostate cancer cell growth and survival. Oncogene. 2016;35(19):2441-52.

139. Vander Griend DJ, Litvinov IV, Isaacs JT. Conversion of androgen receptor signaling from a growth suppressor in normal prostate epithelial cells to an oncogene in prostate cancer cells involves a gain of function in c-Myc regulation. Int J Biol Sci. 2014;10(6): $627-42$.
140. Antony L, van der Schoor F, Dalrymple SL, Isaacs JT. Androgen receptor (AR) suppresses normal human prostate epithelial cell proliferation via AR/beta-catenin/TCF-4 complex inhibition of cMYC transcription. Prostate. 2014;74(11):1118-31.

141. Chen H, Tu SW, Hsieh JT. Down-regulation of human DAB2IP gene expression mediated by polycomb Ezh2 complex and histone deacetylase in prostate cancer. J Biol Chem. 2005;280(23): 22437-44.

142. Min J, Zaslavsky A, Fedele G, McLaughlin SK, Reczek EE, De Raedt T, et al. An oncogene-tumor suppressor cascade drives metastatic prostate cancer by coordinately activating Ras and nuclear factor-kappaB. Nat Med. 2010;16(3):286-94.

143. Aytes A, Mitrofanova A, Lefebvre C, Alvarez MJ, Castillo-Martin $\mathrm{M}$, Zheng T, et al. Cross-species regulatory network analysis identifies a synergistic interaction between FOXM1 and CENPF that drives prostate cancer malignancy. Cancer Cell. 2014;25(5):63851 .

144. Aytes A, Mitrofanova A, Kinkade CW, Lefebvre C, Lei M, Phelan $\mathrm{V}$, et al. ETV4 promotes metastasis in response to activation of PI3-kinase and Ras signaling in a mouse model of advanced prostate cancer. Proc Natl Acad Sci U S A. 2013;110(37):E3506-15.

145. Mitrofanova A, Aytes A, Zou M, Shen MM, Abate-Shen C, Califano A. Predicting drug response in human prostate cancer from preclinical analysis of in vivo mouse models. Cell Rep. 2015;12(12):2060-71.

146. Kar S, Sengupta D, Deb M, Pradhan N, Patra SK. SOX2 function and Hedgehog signaling pathway are co-conspirators in promoting androgen independent prostate cancer. Biochim Biophys Acta. 2017;1863(1):253-65.

147. Ding L, Chen S, Liu P, Pan Y, Zhong J, Regan KM, et al. CBP loss cooperates with PTEN haploinsufficiency to drive prostate cancer: implications for epigenetic therapy. Cancer Res. 2014;74(7): 2050-61.

148. Li D, Sun H, Sun WJ, Bao HB, Si SH, Fan JL, et al. Role of RbBP5 and H3K4me3 in the vicinity of Snail transcription start site during epithelial-mesenchymal transition in prostate cancer cell. Oncotarget. 2016;7(40):65553-67.

149. Dong C, Wu Y, Yao J, Wang Y, Yu Y, Rychahou PG, et al. G9a interacts with Snail and is critical for Snail-mediated E-cadherin repression in human breast cancer. J Clin Invest. 2012;122(4): 1469-86.

150. Liu S, Ye D, Guo W, Yu W, He Y, Hu J, et al. G9a is essential for EMT-mediated metastasis and maintenance of cancer stem celllike characters in head and neck squamous cell carcinoma. Oncotarget. 2015;6(9):6887-901.

151. Liu Y, Zeng S, Jiang X, Lai D, Su Z. SOX4 induces tumor invasion by targeting EMT-related pathway in prostate cancer. Tumour Biol. 2017;39(5):1010428317694539.

152. Bilir B, Osunkoya AO, WGt W, Sannigrahi S, Lefebvre V, Metzger D, et al. SOX4 is essential for prostate tumorigenesis initiated by PTEN ablation. Cancer Res. 2016;76(5):1112-21.

153. Mahajan K, Malla P, Lawrence HR, Chen Z, Kumar-Sinha C, Malik R, et al. ACK1/TNK2 regulates histone H4 Tyr88phosphorylation and AR gene expression in castration-resistant prostate cancer. Cancer Cell. 2017;31(6):790-803.e8. 